\title{
Passive immunity and colostrum management practices on Ontario dairy farms and auction facilities: A cross-sectional study
}

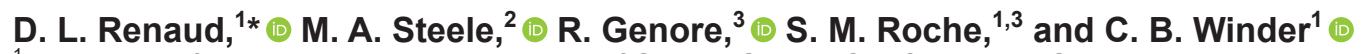 \\ ${ }^{1}$ Department of Population Medicine, University of Guelph, Guelph, ON, Canada, N1G 2W1 \\ ${ }^{2}$ Department of Animal Biosciences, University of Guelph, Guelph, ON, Canada, N1G 2W1 \\ ${ }^{3}$ ACER Consulting, 100 Stone Rd. W., Guelph, ON, Canada, N1G 5L3
}

\section{ABSTRACT}

Failed transfer of passive immunity (FTPI) in dairy calves has substantial health consequences, but there have been no recently published estimates of the prevalence of FTPI on Ontario dairy farms. The major objectives of this cross-sectional study were to determine the level of FTPI in dairy calves across the province of Ontario and to determine colostrum management practices used. A convenience sample of 109 dairy farms in Ontario were visited from June to August 2019, along with 4 auction facilities from January to February 2019. At the single visit to each dairy farm, an in-person questionnaire was administered, and all calves between $24 \mathrm{~h}$ and $9 \mathrm{~d}$ of age had a blood sample collected to determine the levels of serum total protein (STP). At the auction facility, a blood sample was collected on all calves that arrived on the day of the visit. The dairy farms were distributed throughout Ontario, and the farms milked on average 151 dairy cows. Of the 444 calves sampled on Ontario dairy farms, $46 \%$ were male, $54 \%$ were female, and the mean weight and age at sampling were $46.3 \mathrm{~kg}$ and $4.4 \mathrm{~d}$, respectively. The mean STP of calves sampled on the dairy farm was $5.69 \mathrm{~g} / \mathrm{dL}$ (standard deviation $=0.78$ ), and 107 calves (24\%) had FTPI. The likelihood of FTPI was not associated with sex (female vs. male, risk ratio $=0.89$, $95 \%$ confidence interval $=0.64-1.24$ ), age (per day, risk ratio $=1.02,95 \%$ confidence interval $=0.94-1.11$ ), or weight (per $\mathrm{kg}$, risk ratio $=0.98,95 \%$ confidence interval $=0.96-1.01)$. In contrast, at the auction facilities, 386 male dairy calves were sampled and had a mean $\mathrm{STP}$ of $5.79 \mathrm{~g} / \mathrm{dL}$ (standard deviation $=0.83$ ). Using a cut point of $\geq 5.2 \mathrm{~g} / \mathrm{dL}, 91$ calves $(24 \%)$ had FTPI. From the in-person questionnaire administered on the

Received March 21, 2020.

Accepted May 5, 2020.

*Corresponding author: renaudd@uoguelph.ca dairy farms, it was reported that the median time to first feeding of colostrum was $2.5 \mathrm{~h}$ (range $=0-12 \mathrm{~h}$ ). The farms reported providing a mean of $3.3,2.9$, and $3.4 \mathrm{~L}$ of colostrum from 0 to $6 \mathrm{~h}$ after birth, 6 to 12 $\mathrm{h}$ after birth, and 12 to $24 \mathrm{~h}$ after birth, respectively. Ninety-one farms (83\%) fed colostrum from the dam of the calf as their predominant source of colostrum. The most common method used to deliver the first feeding of colostrum was a nipple bottle (89 farms, $82 \%)$. Twenty-seven farms (25\%) reported managing colostrum differently for male calves, which included a different colostrum source, use of poorer quality colostrum, a smaller quantity of colostrum, a longer time from birth to feeding, and generally having a lower focus on colostrum management for male calves. The prevalence of FTPI on Ontario dairy farms appears to have decreased since previous estimates, and substantial room for improvement remains. Although no overall differences were found in FTPI between male and female calves, differential reported colostrum management by sex indicates this may be a risk for male calves on a proportion of Ontario dairy farms.

Key words: calves, failed transfer of passive immunity, serum total protein

\section{INTRODUCTION}

Dairy calves are born agammaglobulinemic and rely on immunoglobulins in colostrum from the dam to achieve passive transfer (Godden, 2008). Passive transfer occurs through transfer of maternal immunoglobulins across the small intestine in the first $24 \mathrm{~h}$ of life (Godden et al., 2019). Without adequate absorption of immunoglobulins, calves will develop failed transfer of passive immunity (FTPI). There are substantial consequences in calves that have FTPI, including an increased risk of mortality, diarrhea, and respiratory disease (Raboisson et al., 2016), making early and adequate intake of high-quality colostrum the most important management practice for young calves (Godden et al., 2019). 
Successful transfer of passive immunity is traditionally defined as $\geq 10 \mathrm{~g} / \mathrm{L}$ of IgG using radial immunodiffusion (Weaver et al., 2000) or $\geq 5.2 \mathrm{~g} / \mathrm{dL}$ using an indirect measure of serum total protein (STP; Buczinski et al., 2018). Four factors have been associated with improved levels of serum IgG: (1) the cleanliness of colostrum, (2) colostrum quality, (3) the quantity of colostrum fed, and (4) how soon colostrum is fed after birth (Godden et al., 2019). Trotz-Williams et al. (2008) completed a study in 2004 that described how some of these factors were managed on Ontario dairy farms and demonstrated that $37.1 \%$ of 151 calves tested on 112 farms had FTPI using STP. As this study was completed almost 2 decades ago, it is necessary to determine whether factors associated with FTPI and level of FTPI in the province have improved over time.

Concern continues that male dairy calves entering the veal industry may not be receiving adequate colostrum management (Renaud et al., 2017) and, as a result, may have higher rates of FTPI than replacement dairy females. Several studies have identified that male calves are more likely to receive colostrum contaminated with bacteria, lower volumes of colostrum, or no colostrum at all (Fecteau et al., 2002; Renaud et al., 2017; Shivley et al., 2019). Additionally, male calves with FTPI have higher rates of mortality and morbidity similar to what is found in female dairy calves (Pardon et al., 2015; Renaud et al., 2018b). As male calves continue to be produced on dairy farms, further exploration is needed on whether there are differences in colostrum management practices.

The objectives of this cross-sectional observational study were to determine the current prevalence of FTPI on Ontario dairy farms and describe management practices that have been associated with decreased levels of FTPI. Secondary objectives were to examine potential calf-level associations with FTPI and health status. We hypothesized that the prevalence of FTPI in dairy calves of Ontario has decreased since it was last measured in 2004. This study is reported following the STROBE-Vet reporting guidelines for observational studies (O'Connor et al., 2016).

\section{MATERIALS AND METHODS}

\section{Study Design, Participants, Data Sources, and Variables}

Before the onset of the study, approval from the University of Guelph animal care committee was obtained (Animal Use Protocol 4190). This study was completed at a convenience sample of dairy farms across Ontario from June to August of 2019. Auction markets across Ontario were also visited from January to February of 2019. Farms were selected through veterinary practices in Ontario that approached dairy clients to assess their willingness to participate in the study, whereas auction facilities were approached by the researchers to recruit them to participate.

Blood samples at the dairy farms were collected from Holstein dairy calves aged 1 to $9 \mathrm{~d}$ on the single visit to the dairy farm, whereas at the auction facility, all calves that arrived at the sale on the day of the visit had blood collected. Age was not known for the calves sampled at the auction facilities; however, the majority of Canadian dairy producers ship their calves at $<14 \mathrm{~d}$ of age (Renaud et al., 2017). Blood samples were taken by the jugular venipuncture of calves using a 20 -gauge 1-inch needle into a $10-\mathrm{mL}$ sterile blood collection tube without anticoagulant (BD Vacutainer; Becton, Dickson and Co., Franklin Lakes, NJ). The blood was allowed to clot and then centrifuged at $1,500 \times g$ for 15 min at approximately $20^{\circ} \mathrm{C}$. The serum was separated and STP was determined using a digital refractometer (Palm Abbe PA202x; Misco, Solon, OH). The refractometer was recalibrated each day before use with distilled water. An STP value of $<5.2 \mathrm{~g} / \mathrm{dL}$ was used as the cutoff point for FTPI (Buczinski et al., 2018). Using an iPad (Apple Inc., Cupertino, CA), calves at dairy farms were also health scored with the Calf Health Scorer app (University of Wisconsin-Madison) by 2 trained technicians. Fecal consistency (McGuirk, 2008), navel inflammation (Fecteau et al., 1997), attitude, respiratory system (McGuirk and Peek, 2014), joint swelling, and rectal temperature were evaluated as previously described by Renaud et al. (2018a). For a calf to be diagnosed as having respiratory disease, the calf must have a cumulative score of $\geq 5$ when evaluating nasal discharge, ocular discharge, ear position, cough score, and rectal temperature. The calf must have a fecal score of 2 or 3 to be classified as having diarrhea (McGuirk, 2008). Calf weight was estimated using a circumferential measurement (heart girth) of calves' chest just caudal to the elbow joint using a soft measuring tape (The Coburn Company Inc., Whitewater, WI) (Heinrichs et al., 2007). Due to the logistical challenges, calves were not health scored or weighed at auction markets.

During the visit to the dairy farm, the person responsible for calf rearing was asked to verbally answer questions posed by a research technician, and their answers were entered into an online survey software (Qualtrics; https://www.qualtrics.com/). No advice or opinions were offered by technicians while the questions were 
answered to limit recall bias. The questionnaire comprised 32 multiple-choice and fill-in-the-blank questions addressing herd demographics, colostrum management, and male dairy calf management. A full version of the questionnaire is available as Supplemental File S1 (https://doi.org/10.3168/jds.2020-18572). The questionnaire was based off a previous survey completed by Trotz-Williams et al. (2008). It was pretested on 3 dairy farms in the Guelph area before beginning data collection to ensure the survey was comprehensive and cohesive.

\section{Sample Size Calculation}

Based on a prevalence sample size calculation, it was determined that 500 calves would need to be sampled. This was calculated based on the assumption that $30 \%$ of calves would have FTPI and the marginal error to the estimate does not exceed $5 \%$ with a $95 \%$ confidence interval (Hajian-Tilaki, 2011). It was also assumed that there could be clustering within the farms and an intraclass correlation coefficient of 0.05 was used to adjust the sample size for clustering (Dohoo et al., 2010).

\section{Statistical Analysis}

Data from surveys were collected on the Qualtrics Surveys app, and data from calf analysis were collected on the University of Wisconsin Calf Health Scorer app. Data were collated in Microsoft Excel (Microsoft Corp., Redmond, WA) and exported into STATA15 (Stata/IC Version 15.1 for Mac, StatCorp, College Station, TX). Descriptive statistics were reviewed for normality and variation. For calves sampled on-farm, univariate associations between calf-level factors (age, sex, and weight) and the outcomes of FTPI, STP, and health score were measured in the population of calves tested on dairy farms. Additionally, FTPI was considered as an explanatory variable for health score models. Individual variables were tested for potential associations with outcome variables using a mixed model adjusting for farm as a random effect. Specifically, linear regression models were used for STP, health score, and respiratory score, whereas logistic regression models were used for FTPI and likelihood of having diarrhea. If more than one explanatory variable was potentially significant $(P$ $<0.20$ ), a multivariate mixed model was built using forward stepwise selection, with farm adjusted for as a random effect. Covariates were kept in the model if $P<0.05$ or if covariates were considered as potential confounders as their removal changed the coefficients by more than $20 \%$.

\section{RESULTS}

\section{Participants}

From January 28 to February 27, 2019, blood was collected from 386 male dairy calves from 4 auction facilities across Ontario; $146(37.8 \%)$ were sampled from facilities in eastern Ontario, and $240(62.2 \%)$ were sampled from facilities in southwestern Ontario. Blood samples were also collected from 460 Holstein calves from 105 dairy farms across Ontario between June and September of 2019. The questionnaire was completed on 109 dairy farms, which included the 105 farms sampled as well as 4 additional farms that did not have calves that met the inclusion criteria for age at the time of the farm visit. Dairy farms were distributed across Ontario, with 49.6, 18.9, 27.0, and 4.5\% located in the southwestern region, northern region, eastern region, and central region of Ontario, respectively. The farms milked, on average, 151 Holstein dairy cows (range = 26 to 850$)$.

\section{Calves Sampled at Auction}

Among calf blood samples collected at auction $(\mathrm{n}=$ $386)$, the mean STP was $5.79 \mathrm{~g} / \mathrm{dL}(\mathrm{SD}=0.83$, range $=4.1-7.9)$ and a total of $91(24 \%)$ of the calves had FTPI. Figure 1 highlights the distribution of the levels of STP in calves sampled at the auction facilities.

\section{Calves Sampled on Dairy Farms}

Of the 460 Holstein calves sampled on dairy farms, 444 calves were confirmed to be less than $10 \mathrm{~d}$ and greater than $24 \mathrm{~h}$ old at the time of sample collection. Of these calves, the mean age at sampling was $4.4 \mathrm{~d}, 203(45.7 \%)$ were male, and $241(54.3 \%)$ were female. Using a cut point of less than $5.2 \mathrm{~g} / \mathrm{dL}$ of STP, the prevalence of FTPI was $24 \%(107 / 440)$. Mean serum total protein was $5.69 \mathrm{~g} / \mathrm{dL}(\mathrm{SD}=0.78$, range $=$ 3.60-8.70) as shown in Figure 2. Weights were obtained for 436 calves, with a mean weight of $46.3 \mathrm{~kg}$ ( $\mathrm{SD}=$ 5.8 , range $=34.0-65.5$ ). Distribution of weight by age is shown in Figure 3, where a large range of weights were present at all ages. Weight and age were not found to be correlated, with a coefficient of correlation of 0.19. Similarly, in this sample, weight, age, and sex were not found to be correlated (weight and sex, 0.05; age and sex, 0.07). Health scores were completed for 301 calves, with a mean score of $3.5(\mathrm{SD}=1.8$, range $=0-14$, median $=4.0)$. Respiratory scores for 287 calves $(95 \%)$ were below 4, and 11 calves scored 4 . Only 3 calves were classified as having respiratory disease (scoring $\geq 5$ ). 
Specific abnormalities in each component of the scoring criteria are described below. For nasal discharge, 12 (4.0\%) calves had a small amount of unilateral cloudy discharge, and only 3 calves had bilateral, cloudy, or excessive mucus discharge. Only $8(2.7 \%)$ calves had a cough that could be induced after stimulation of the trachea, $14(4.7 \%)$ calves had ocular discharge, 12 (4.0\%) calves had an ear flick or head shake, and 62 $(20.6 \%)$ calves had a rectal temperature $\geq 39.5^{\circ} \mathrm{C}$. Feces was considered normal (score 0) for 72 calves (24\%), semi-formed (score 1) for 151 calves $(54 \%)$, loose (score 2 ) for 49 calves (16\%), and watery (score 3) for 19 calves $(6 \%)$. Therefore, $68(22 \%)$ of calves scored had diarrhea.

\section{Calves Sampled on Dairy Farms: Associations with FTPI}

Age, weight, and sex were tested individually for potential associations with FTPI and STP, accounting for clustering at the farm level using a mixed model. Likelihood of FTPI was not associated with sex [female vs. male, odd ratio $(\mathbf{O R})=0.89,95 \% \mathrm{CI}=0.49-1.64]$, age (per day, $\mathrm{OR}=1.04,95 \% \mathrm{CI}=0.91-1.12$ ), or weight (per kg, OR $=0.97,95 \% \mathrm{CI}=0.93-1.02$ ). Serum total protein was also unrelated to sex (female vs. male, $\beta=$
$-0.02 \mathrm{~g} / \mathrm{dL}, 95 \% \mathrm{CI}=-0.18$ to 0.12 ), age (per day, $\beta$ $=-0.2 \mathrm{~g} / \mathrm{dL}, 95 \% \mathrm{CI}=-0.05$ to 0.01 ), and weight (per kg, $\beta=0.03 \mathrm{~g} / \mathrm{dL}, 95 \% \mathrm{CI}=-0.01$ to 0.02 ).

\section{Calves Sampled on Dairy Farms: Associations with Health Status}

Age, weight, sex, and FTPI were tested individually for potential associations with overall health score, respiratory score, and likelihood of having diarrhea (fecal score $>1$ ), using mixed models to account for clustering at the farm level. Higher health scores (more signs of clinical illness) were more likely in older calves (per day of age, $\beta=0.91 ; 95 \% \mathrm{CI}=0.02-0.17 ; P=0.01$ ). Weight, sex, and FTPI were not found to be associated with overall health score in our data set $(P>0.20)$. Respiratory score was associated with age, with higher scores being more common in older calves (per day of age, $\beta=0.10,95 \%$ CI $=0.05-0.16)$. Higher weights were associated with lower respiratory scores, using a liberal $P$-value $(\beta=0.02 ; 95 \% \mathrm{CI}=-0.003$ to $0.04 ; P$ $=0.10)$, and calves with FTPI had higher respiratory scores $(\beta=0.19 ; 95 \% \mathrm{CI}=-0.09$ to $0.47 ; P=0.19)$. When a multivariate mixed model was built, neither weight nor FTPI was retained, nor did they appear to confound the association between age and respira-

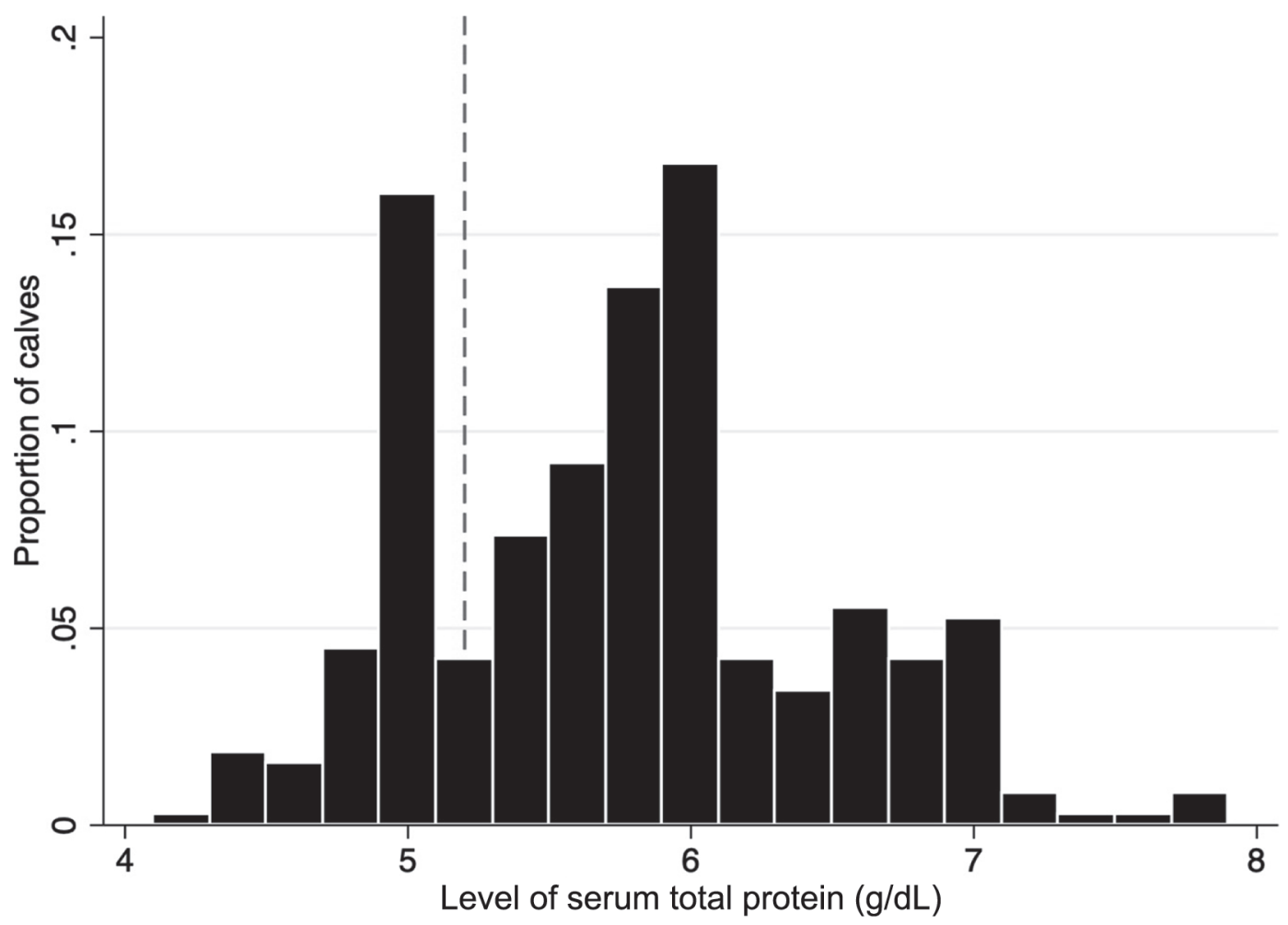

Figure 1. The distribution of serum total protein from blood samples collected from 386 calves in Ontario auction facilities. The dashed line indicates a serum total protein level of $5.2 \mathrm{~g} / \mathrm{dL}$. 
tory score when removed from the model. Older calves were found to be more likely to have diarrhea (fecal score of 2 or $3 ; \mathrm{OR}=1.30 ; 95 \% \mathrm{CI}=1.12-1.50 ; P<$ 0.001). Weight, sex, and FTPI were not found to be associated with the likelihood of diarrhea in our data set $(P>0.20)$.

\section{Colostrum Management Practices}

The median time that farms reported milking the majority of their cows for the first time after calving was $3.5 \mathrm{~h}$ (range $=0-24 \mathrm{~h}$ ). For first feeding of colostrum, farms reported that the median time was 2.5 $\mathrm{h}$ (range $=0-12 \mathrm{~h}$ ). Most respondents fed colostrum from the dam of the calf as their predominant source of colostrum and used mostly fresh colostrum (Table 1). The farms reported providing a mean of $3.3 \mathrm{~L}$ (range $=$ $1.5-6 \mathrm{~L}), 2.9 \mathrm{~L}($ range $=0-10 \mathrm{~L})$, and $3.4 \mathrm{~L}($ range $=$ 0-16 L) of colostrum from 0 to $6 \mathrm{~h}$ after birth, 6 to $12 \mathrm{~h}$ after birth, and 12 to $24 \mathrm{~h}$ after birth, respectively. The predominant feeding method used to deliver the first feeding of colostrum was a nipple bottle or a bucket with a nipple (Table 1). A total of 54 farms (48.6\%) indicated that they tested colostrum quality. Of those that tested, 24 farms (45.3\%) used an optical Brix refractometer, 4 farms (7.5\%) used a digital refractometer, and 3 farms $(5.7 \%)$ used a colostrometer. It is interesting to note that 22 farms $(41.5 \%)$ indicated they solely measured colostrum quality visually. Eighty-one of the farms $(75.7 \%)$ stored colostrum, with a freezer, refrigerator, or combination of the 2 used by 53 farms (49.1\%), 14 farms (13.0\%), and 7 farms (6.5\%), respectively. Transition milk (defined as milk harvested from milkings 2-6 after calving; Godden, 2008) was fed on 83 $(78.3 \%)$ of the farms. Of the farms that fed transition milk, it was provided for a median of $3.0 \mathrm{~d}$ (range $=1-5$ d). Only 27 farms (25.5\%) indicated that they tested for FTPI, with 19 farms (17.9\%) indicating their veterinarian took samples occasionally, 4 farms (3.8\%) indicating their veterinarian took samples regularly, and 4 farms $(3.8 \%)$ indicating they took samples on their own. On all farms visited, they estimated that their level of FTPI was 21.5\% (range $=0-100 \%$ ); however, 18 farms said that they were not sure of the number.

\section{Male Calf Colostrum Management}

Most of the farms reported that male calves were sold at $\leq 1 \mathrm{wk}$ of age $(41.7 \%)$ or between 1 and $4 \mathrm{wk}$ of age $(38.0 \%)$, with only $13 \%$ of the calves being raised to

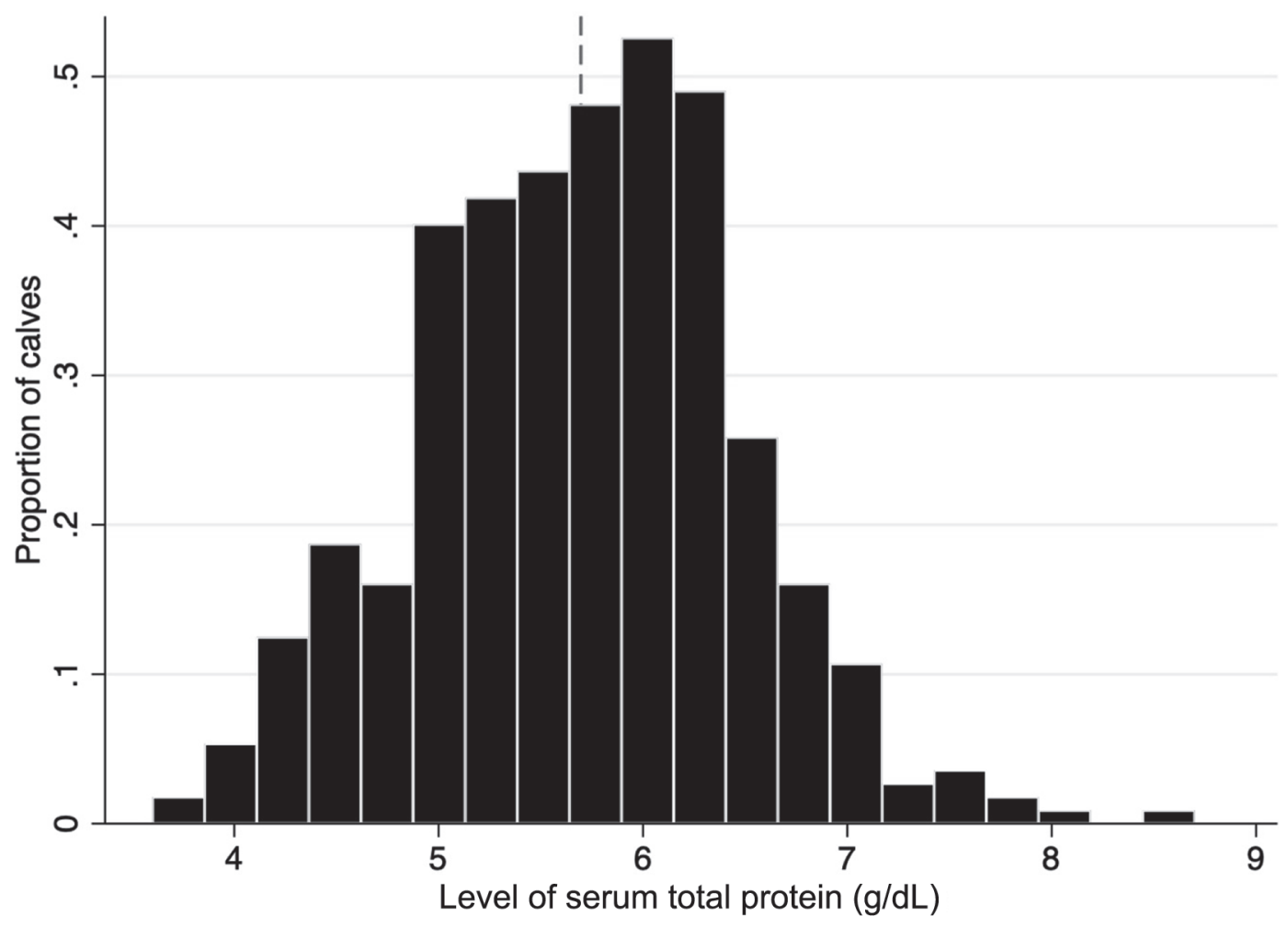

Figure 2. The distribution of serum total protein from blood samples collected from 440 calves sampled from Ontario dairy farms. The dashed line indicates a serum total protein level of $5.5 \mathrm{~g} / \mathrm{dL}$. 
finishing or sold at weaning. Seven percent of farms had differing selling practices depending on either genetic value, market value, or breed.

Twenty-seven farms $(25.2 \%)$ indicated they managed colostrum differently for male calves. Of the differences provided by those who recorded that differential management was used, 30.4\% (7 farms), 13.4\% (3 farms), $13.4 \%$ (3 farms), 39.1\% (9 farms), and $4.3 \%$ (1 farm) indicated that the difference was through the source of colostrum, poorer quality colostrum, lower quantity of colostrum, lower focus on colostrum management, and longer time from birth to colostrum feeding, respectively. When asked whether they thought males and females had the same level of FTPI, 13 farms (12.2\%) thought females would have higher FTPI, 24 farms (22.4\%) thought males would have higher FTPI, 42 farms $(39.3 \%)$ thought they would be the same, and 28 farms $(26.2 \%)$ were unsure.

\section{DISCUSSION}

This study indicates that the level of FTPI and colostrum management practices could be improving compared with previous estimates on Ontario dairy farms. No differences in the level of FTPI were found between male and female dairy calves; however, we identified subtle differences in colostrum management. There are some limitations to consider in the conduct of the study. First, this study did not use a random sample of dairy farms, and the farms were larger than the average dairy farm in Ontario $(\mathrm{n}=93$ cows; Canadian Dairy Information Center, 2019) and Canada ( $\mathrm{n}=93$ cows; Canadian Dairy Information Center, 2019). Hence, this could be an under- or overestimation of FTPI; however, we sampled farms across Ontario and because farms of all sizes send calves to auction facilities, we feel this has not substantially affected our results. We also did not use radial immunodiffusion to measure the levels of $\operatorname{IgG}$ and instead used an indirect measure of STP. However, STP is still the best on-farm measure of FTPI from 1 to $9 \mathrm{~d}$ of age (Wilm et al., 2018) and likely had little effect on the results of this study. A further limitation that could have affected the results determined at auction is that the age of the calves was not known. However, Renaud et al. (2018c) found that when calves arrived at a veal facility at an unknown age, STP remained highly correlated with serum $\operatorname{IgG}\left(\mathrm{R}^{2}=0.75\right)$. Additionally, a survey on 52 Ontario dairy farms found that only $19 \%$ kept male calves on the source dairy farm beyond $7 \mathrm{~d}$ of age (Renaud et al., 2018d), suggesting the measurement of STP should be an accurate indirect measure of IgG at auction facilities in Ontario.

The level of FTPI identified in this group of 846 calves was $24 \%$. The level of FTPI seems to have im-

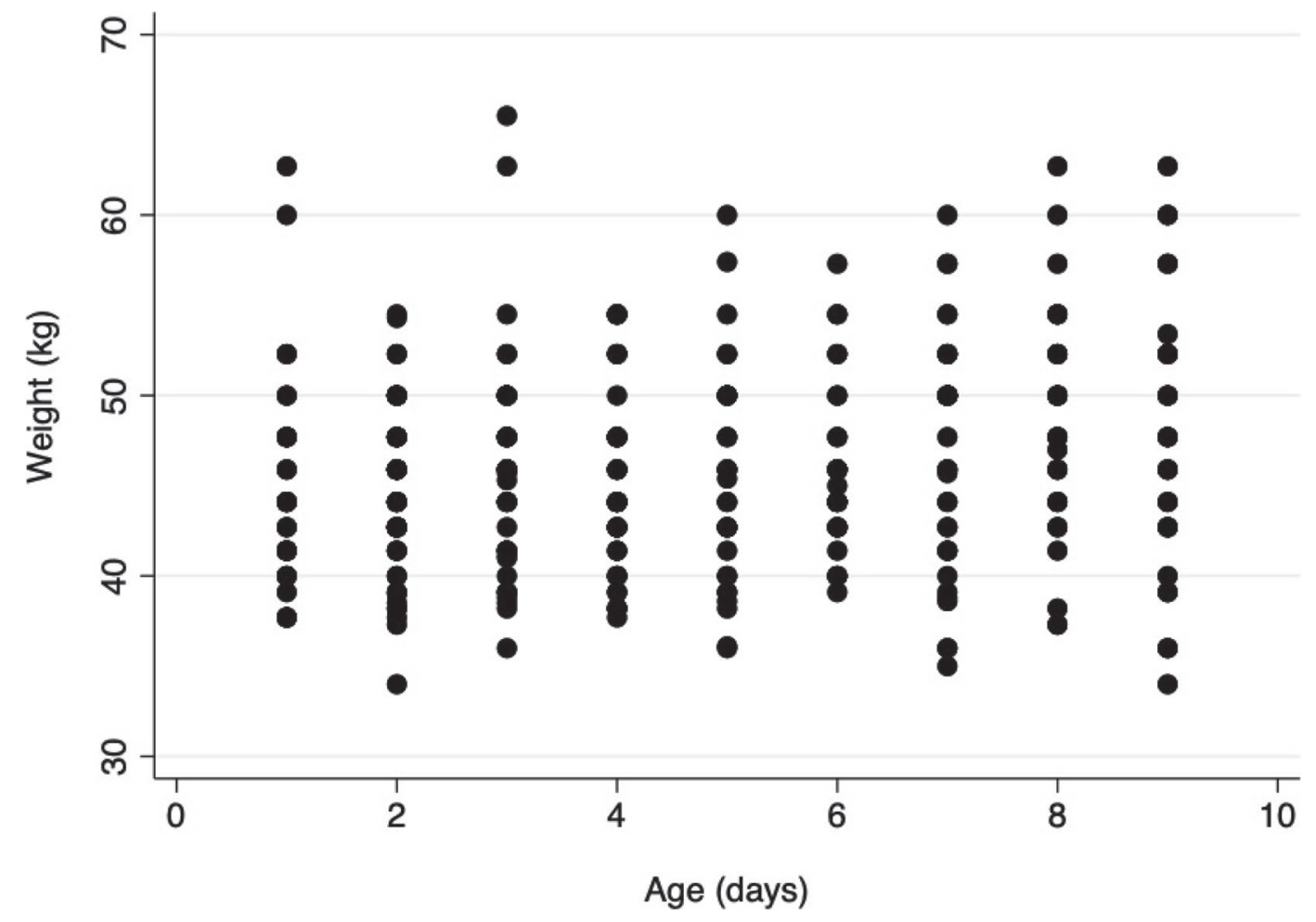

Figure 3. Scatterplot showing the distribution of weight by day of age of 436 calves sampled from Ontario dairy farms. 


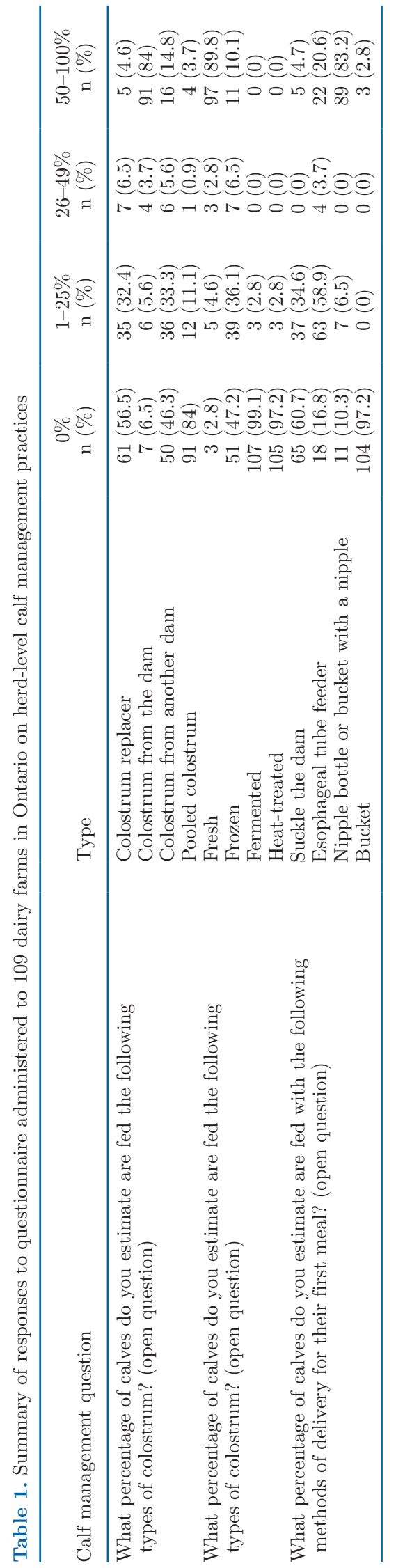

proved since 2004 when it was last estimated on Ontario dairy farms to be $37 \%$ (Trotz-Williams et al., 2008). In similar epidemiological studies, the rates of FTPI were found to be lower, with $15.6 \%$ of 2,545 calves having FTPI on 104 US operations (Shivley et al., 2018), and $19.2 \%$ of 1,816 calves having FTPI on 394 US operations in a 2007 study (Beam et al., 2009); however, other studies found $41.9 \%$ FTPI in sampling 253 calves from 23 farms in Australia (Abuelo et al., 2019) and $33.0 \%$ FTPI in 3,819 calves on 107 farms in New Zealand (Cuttance et al., 2017). Given its importance and association with improved levels of mortality and morbidity in both male (Pardon et al., 2015; Renaud et al., 2018b) and female dairy calves (Raboisson et al., 2016), there is a need for attention given to FTPI on farms. In addition, it has been proposed that $<10 \%$ of calves should have an STP of $<5.1 \mathrm{~g} / \mathrm{dL}$ and $>40 \%$ of calves should have an STP of $\geq 6.2 \mathrm{~g} / \mathrm{dL}$ (Godden et al., 2019) suggesting there is considerable room for improvement in the management of colostrum. Improvement could be accomplished through routine STP sampling which, when benchmarked, has been shown to improve levels of FTPI (Atkinson et al., 2017; Sumner et al., 2018). Benchmarking may also improve producer perceptions of the capacity of veterinarians in advising on calves and strengthen the relationship between veterinarian and producer (Sumner et al., 2020). However, this routine monitoring of FTPI was only conducted on $7.6 \%$ of farms, suggesting an opportunity for veterinarians and producers to work together to make this a more regular and effective practice.

In our sample of calves on dairy farms, older calves were more likely to have higher health scores, including more signs of both respiratory disease and calf diarrhea. As our sample was only from calves $9 \mathrm{~d}$ of age or less, older calves may reflect additional time at risk to develop clinical signs of disease. Weight was not found to be associated with health; a recent study in the United Kingdom similarly found no association between birth weight and calf health (Glover et al., 2019). Weight of calves in our study likely reflects both birth weight and early life nutrition. A wide variety of farms were sampled in our study, with few calves sampled per farm, and as a result we may not have been able to identify potential association between weight and health. That FTPI was not associated with health score was similar to findings of Mahendran et al. (2017), although in our study this was a secondary objective and likely required more calves sampled per farm to determine the nature of this potential association.

Colostrum management practices seem to have improved since the last survey completed in 2004 (Trotz-Williams et al., 2008). Overall, a higher volume of colostrum is being fed, with almost $1 \mathrm{~L}$ more co- 
lostrum being provided 0 to $6 \mathrm{~h}$ after birth, 6 to 12 $\mathrm{h}$ after birth, and 12 to $24 \mathrm{~h}$ after birth, respectively. Given the importance of colostrum volume having a positive association with STP and reducing the odds of FTPI (Chigerwe et al., 2008; Lora et al., 2018; Renaud et al., 2020), this is a positive change that could have resulted in the improvement seen in the level of FTPI. Colostrum replacer has also increased in use as a source of colostrum; however, pooled colostrum and colostrum from another cow that is not the dam has also increased. Colostrum that has been pooled from multiple cows in particular has been associated with a higher level of FTPI, and immunoglobulins in pooled colostrum may be diluted with the addition of poorquality colostrum (Weaver et al., 2000; Beam et al., 2009). Allowing calves to suckle from the dam has also been found to be associated with an increased level of FTPI (Brignole and Stott, 1980; Besser et al., 1991; Beam et al., 2009) and it has increased in its use as a primary colostrum feeding method. These high-risk management practices should be discouraged to ensure rates of FTPI do not increase and have more calves achieving successful passive transfer.

Differential colostrum management between male and female dairy calves was identified on $25 \%$ of the farms visited. These differences in colostrum management have been previously reported in the literature (Fecteau et al., 2002; Shivley et al., 2019; Renaud et al., 2020); however, despite the perceived importance of the differences, such as a lower quantity of colostrum, lower focus on colostrum management, and longer time from birth to colostrum feeding, no differences in FTPI or STP were identified between male and female dairy calves. This is similar to what has been described previously in the literature (Filteau et al., 2003; TrotzWilliams et al., 2008; Barry et al., 2019) suggesting that there may not be a substantial difference in the levels of IgG for calves.

\section{CONCLUSIONS}

The prevalence of FTPI on Ontario dairy farms was found to be $24 \%$. Although this level is lower than previous estimates, there remains room for improvement. A higher volume of colostrum was being fed compared with previous estimates in Ontario; however, more producers were using pooled colostrum and were allowing more calves to suckle from the dam. Although no overall differences were found in FTPI between male and female calves, differential reported colostrum management by sex indicates this may be a risk for male calves on a proportion of Ontario dairy farms.

\section{ACKNOWLEDGMENTS}

The authors thank Veal Farmers of Ontario (Guelph, ON, Canada) and the Ontario Veterinary College (Guelph, ON, Canada) for their funding support in the completion of this project. We also thank the producers who participated in this research and Joanne Marshall and Brenna Tuer for collecting the samples. The authors have not stated any conflicts of interest.

\section{REFERENCES}

Abuelo, A., P. Havrlant, N. Wood, and M. Hernandez-Jover. 2019. An investigation of dairy calf management practices, colostrum quality, failure of transfer of passive immunity, and occurrence of enteropathogens among Australian dairy farms. J. Dairy Sci. 102:8352-8366. https://doi.org/10.3168/jds.2019-16578.

Atkinson, D. J., M. A. G. von Keyserlingk, and D. M. Weary. 2017. Benchmarking passive transfer of immunity and growth in dairy calves. J. Dairy Sci. 100:3773-3782. https://doi.org/10.3168/jds .2016-11800.

Barry, J., E. A. M. Bokkers, D. P. Berry, I. J. M. de Boer, J. McClure, and E. Kennedy. 2019. Associations between colostrum management, passive immunity, calf-related hygiene practices, and rates of mortality in preweaning dairy calves. J. Dairy Sci. 102:1026610276. https://doi.org/10.3168/jds.2019-16815.

Beam, A. L., J. E. Lombard, C. A. Kopral, L. P. Garber, A. L. Winter, J. A. Hicks, and J. L. Schlater. 2009. Prevalence of failure of passive transfer of immunity in newborn heifer calves and associated management practices on US dairy operations. J. Dairy Sci. 92:3973-3980. https://doi.org/10.3168/jds.2009-2225.

Besser, T. E., C. C. Gay, and L. Pritchett. 1991. Comparison of three methods of feeding colostrum to dairy calves. J. Am. Vet. Med. Assoc. 198:419-422.

Brignole, T. J., and G. H. Stott. 1980. Effect of suckling followed by bottle feeding colostrum on immunoglobulin absorption and calf survival. J. Dairy Sci. 63:451-456. https://doi.org/10.3168/jds .S0022-0302(80)82952-3.

Buczinski, S., E. Gicquel, G. Fecteau, Y. Takwoingi, M. Chigerwe, and J. M. Vandeweerd. 2018. Systematic review and meta-analysis of diagnostic accuracy of serum refractometry and brix refractometry for the diagnosis of inadequate transfer of passive immunity in calves. J. Vet. Intern. Med. 32:474-483. https://doi.org/10.1111/ jvim.14893.

Canadian Dairy Information Center. 2019. Overview of Canadian dairy industry at the farm level. Accessed Mar. 21, 2020. http: //www.dairyinfo.gc.ca/index_e.php?s1=dff-fcil\&s2=farm-ferme\& $\mathrm{s} 3=\mathrm{nb}$.

Chigerwe, M., J. W. Tyler, L. G. Schultz, J. R. Middleton, B. J. Steevens, and J. N. Spain. 2008. Effect of colostrum administration by use of oroesophageal intubation on serum IgG concentrations in Holstein bull calves. Am. J. Vet. Res. 69:1158-1163. https: //doi.org/10.2460/ajvr.69.9.1158.

Cuttance, E. L., W. A. Mason, R. A. Laven, J. McDermott, and C. V. C. Phyn. 2017. Prevalence and calf-level risk factors for failure of passive transfer in dairy calves in New Zealand. N. Z. Vet. J. 65:297-304. https://doi.org/10.1080/00480169.2017.1361876.

Dohoo, I., W. Martin, and H. Stryhn. 2010. Sampling. Pages 33-72 in Veterinary Epidemiologic Research. 2nd ed. VER Inc., Charlottetown, PEI, Canada.

Fecteau, G., P. Baillargeon, R. Higgins, J. Paré, and M. Fortin. 2002. Bacterial contamination of colostrum fed to newborn calves in Québec dairy herds. Can. Vet. J. 43:523-527.

Fecteau, G., J. Paré, D. C. Van Metre, B. P. Smith, C. A. Holmberg, W. Guterbock, and S. Jang. 1997. Use of a clinical sepsis score for predicting bacteremia in neonatal dairy calves on a calf rearing farm. Can. Vet. J. 38:101-104. 
Filteau, V., É. Bouchard, G. Fecteau, L. Dutil, and D. DuTremblay. 2003. Health status and risk factors associated with failure of passive transfer of immunity in newborn beef calves in Québec. Can. Vet. J. 44:907-913.

Glover, I. D., D. C. Barrett, and K. K. Reyher. 2019. Little association between birth weight and health of preweaned dairy calves. Vet. Rec. 184:477. https://doi.org/10.1136/vr.105062.

Godden, S. 2008. Colostrum management for dairy calves. Vet. Clin. North Am. Food Anim. Pract. 24:19-39. https://doi.org/10.1016/ j.cvfa.2007.10.005.

Godden, S. M., J. E. Lombard, and A. R. Woolums. 2019. Colostrum management for dairy calves. Vet. Clin. North Am. Food Anim. Pract. 35:535-556. https://doi.org/10.1016/j.cvfa.2019.07.005.

Hajian-Tilaki, K. 2011. Sample size estimation in epidemiologic studies. Caspian J. Intern. Med. 2:289-298.

Heinrichs, A. J., H. N. Erb, G. W. Rogers, J. B. Cooper, and C. M. Jones. 2007. Variability in Holstein heifer heart-girth measurements and comparison of prediction equations for live weight. Prev. Vet. Med. 78:333-338. https://doi.org/10.1016/j.prevetmed 2006.11.002.

Lora, I., A. Barberio, B. Contiero, P. Paparella, L. Bonfanti, M. Brscic, A. L. Stefani, and F. Gottardo. 2018. Factors associated with passive immunity transfer in dairy calves: Combined effect of delivery time, amount and quality of the first colostrum meal. Animal 12:1041-1049. https://doi.org/10.1017/S1751731117002579.

Mahendran, S. A., R. Booth, L. Beekhuis, A. Manning, T. Blackmore, A. Vanhoudt, and N. Bell. 2017. Assessing the effects of weekly preweaning health scores on dairy calf mortality and productivity parameters: Cohort study. Vet. Rec. 181:196. https://doi.org/10 $.1136 / v r .104197$.

McGuirk, S. M. 2008. Disease management of dairy calves and heifers. Vet. Clin. North Am. Food Anim. Pract. 24:139-153. https://doi .org/10.1016/j.cvfa.2007.10.003.

McGuirk, S. M., and S. F. Peek. 2014. Timely diagnosis of dairy calf respiratory disease using a standardized scoring system. Anim. Health Res. Rev. 15:145-147. https://doi.org/10.1017/ S1466252314000267.

O'Connor, A. M., J. M. Sargeant, I. R. Dohoo, H. N. Erb, M. Cevallos, M. Egger, A. K. Ersboll, S. W. Martin, L. R. Nielsen, D. L. Pearl, D. U. Pfeiffer, J. Sanchez, M. E. Torrence, H. Vigre, C. Waldner, and M. P. Ward. 2016. Explanation and elaboration document for the STROBE-Vet statement: Strengthening the reporting of observational studies in epidemiology - veterinary extension. Zoonoses Public Health 63:662-698. https://doi.org/10.1111/zph.12315.

Pardon, B., J. Alliët, R. Boone, S. Roelandt, B. Valgaeren, and P. Deprez. 2015. Prediction of respiratory disease and diarrhea in veal calves based on immunoglobulin levels and the serostatus for respiratory pathogens measured at arrival. Prev. Vet. Med. 120:169-176. https://doi.org/10.1016/j.prevetmed.2015.04.009.

Raboisson, D., P. Trillat, and C. Cahuzac. 2016. Failure of passive immune transfer in calves: A meta-analysis on the consequences and assessment of the economic impact. PLoS One 11:e0150452. https: //doi.org/10.1371/journal.pone.0150452.

Renaud, D. L., T. F. Duffield, S. J. LeBlanc, S. Ferguson, D. B. Haley, and D. F. Kelton. 2018a. Risk factors associated with mortality at a milk-fed veal calf facility: A prospective cohort study. J. Dairy Sci. 101:2659-2668. https://doi.org/10.3168/jds.2017-13581.

Renaud, D. L., T. F. Duffield, S. J. LeBlanc, D. B. Haley, and D. F. Kelton. 2017. Management practices for male calves on Canadian dairy farms. J. Dairy Sci. 100:6862-6871. https://doi.org/10.3168/ jds.2017-12750.
Renaud, D. L., T. F. Duffield, S. J. LeBlanc, D. B. Haley, and D. F. Kelton. 2018b. Clinical and metabolic indicators associated with early mortality at a milk-fed veal facility: A prospective case-control study. J. Dairy Sci. 101:2669-2678. https://doi.org/10.3168/ jds.2017-14042.

Renaud, D. L., T. F. Duffield, S. J. LeBlanc, and D. F. Kelton. 2018c. Short communication: Validation of methods for practically evaluating failed passive transfer of immunity in calves arriving to a veal facility. J. Dairy Sci. 101:9516-9520. https://doi.org/10.3168/ jds.2018-14723.

Renaud, D. L., D. F. Kelton, S. J. LeBlanc, D. B. Haley, and T. F. Duffield. 2018d. Calf management risk factors on dairy farms associated with male calf mortality on veal farms. J. Dairy Sci. 101:1785-1794. https://doi.org/10.3168/jds.2017-13578.

Renaud, D. L., K. M. Waalderbos, L. Beavers, T. F. Duffield, K. E. Leslie, and M. C. Windeyer. 2020. Risk factors associated with failed transfer of passive immunity in male and female dairy calves: A 2008 retrospective cross-sectional study. J. Dairy Sci. 103:35213528. https://doi.org/10.3168/jds.2019-17397.

Shivley, C. B., J. E. Lombard, N. J. Urie, D. M. Haines, R. Sargent, C. A. Kopral, T. J. Earleywine, J. D. Olson, and F. B. Garry. 2018. Preweaned heifer management on US dairy operations: Part II. Factors associated with colostrum quality and passive transfer status of dairy heifer calves. J. Dairy Sci. 101:9185-9198. https:// doi.org/10.3168/jds.2017-14008.

Shivley, C. B., J. E. Lombard, N. J. Urie, D. M. Weary, and M. A. G. von Keyserlingk. 2019. Management of preweaned bull calves on dairy operations in the United States. J. Dairy Sci. 102:4489-4497. https://doi.org/10.3168/jds.2018-15100.

Sumner, C. L., M. A. G. von Keyserlingk, and D. M. Weary. 2018. How benchmarking motivates farmers to improve dairy calf management. J. Dairy Sci. 101:3323-3333. https://doi.org/10.3168/jds .2017-13596.

Sumner, C. L., M. A. G. von Keyserlingk, and D. M. Weary. 2020. How benchmarking promotes farmer and veterinarian cooperation to improve calf welfare. J. Dairy Sci. 103:702-713. https://doi.org/ 10.3168/jds.2019-16338.

Trotz-Williams, L.A., K. E. Leslie, and A. Peregrine. 2008. Passive immunity in Ontario dairy calves and investigation of its association with calf management practices. J. Dairy Sci. 91:3840-3849. https: //doi.org/10.3168/jds.2007-0898.

Weaver, D. M., J. W. Tyler, D. C. VanMetre, D. E. Hostetler, and G. M. Barrington. 2000. Passive transfer of colostral immunoglobulins in calves. J. Vet. Intern. Med. 14:569-577. https://doi.org/10 $.1111 /$ j.1939-1676.2000.tb02278.x.

Wilm, J., J. H. C. Costa, H. W. Neave, D. M. Weary, and M. A. G. von Keyserlingk. 2018. Technical note: Serum total protein and immunoglobulin $\mathrm{G}$ concentrations in neonatal dairy calves over the first 10 days of age. J. Dairy Sci. 101:6430-6436. https://doi.org/ $10.3168 /$ jds.2017-13553.

\section{ORCIDS}

D. L. Renaud (๑) https://orcid.org/0000-0002-3439-3987

M. A. Steele $\odot$ https://orcid.org/0000-0001-6941-6205

R. Genore (๑) https://orcid.org/0000-0001-7737-6047

C. B. Winder ๑ https://orcid.org/0000-0002-7314-3657 